\title{
Erratum to: Genetic variants of ESR1 and SGSM3 are associated with the susceptibility of breast cancer in the Chinese population
}

\author{
Tan $\operatorname{Tan}^{1} \cdot$ Kai Zhang ${ }^{2} \cdot$ Wenjun Chen ${ }^{1}$
}

Published online: 11 October 2016

(C) The Japanese Breast Cancer Society 2016

\section{Erratum to: Breast Cancer}

DOI 10.1007/s12282-016-0712-5

The correct name of the corresponding author should be given as Wenjun Chen, not Wenjun Chen Sun.

The online version of the original article can be found under doi:10.1007/s12282-016-0712-5.

\section{Wenjun Chen}

chenwenjun2016@163.com

1 Department of General Surgery, Jiangsu Province Geriatric Hospital, Jiangsu Road No. 65, Nanjing 210008, China

2 Department of General Surgery, The Affiliated Drum Tower Hospital of Medical School of Nanjing University, Nanjing 210008, China 